\title{
Prenatal Diagnosis of Congenital Malformations in Douala General Hospital
}

\author{
Tchente Nguefack Charlotte1,2*, Nzesseu Djomo Aurore ${ }^{2,3}$, Brulet Charlotte ${ }^{4}$, Barla Esther5, \\ Belley Priso Eugene ${ }^{2,6}$

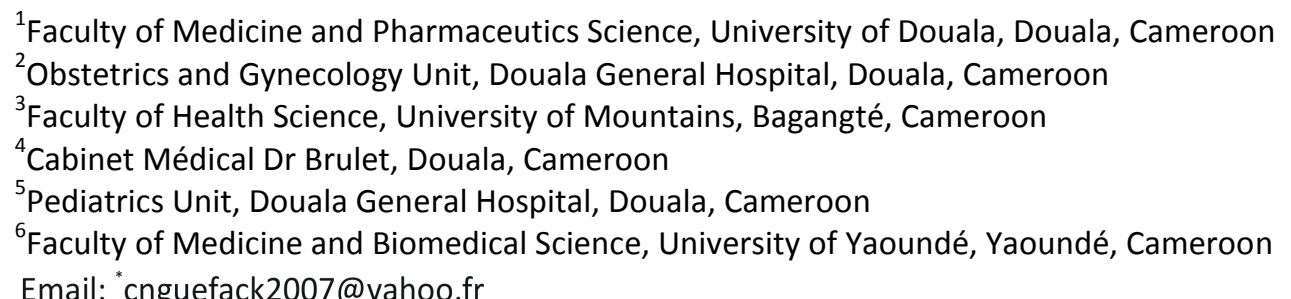 \\ Email: "cnguefack2007@yahoo.fr
}

Received 13 November 2015; accepted 11 December 2015; published 14 December 2015

Copyright (C) 2015 by authors and Scientific Research Publishing Inc.

This work is licensed under the Creative Commons Attribution International License (CC BY).

http://creativecommons.org/licenses/by/4.0/

(c) (i) Open Access

\section{Abstract}

Objectives: To determine the prevalence of congenital malformations and the proportion of cases diagnosed before birth; to specify this proportion according to the type of malformation and the sonographer qualification. Methods: It was a cross-sectional study carried out at the Douala General Hospital in the obstetric and neonatal units over a period of 42 months, from January 2008 to June 2012. The procedure consisted of; firstly an explanation of the study purpose with consent of parents obtained, thereafter, the parents were interviewed and data extracted from their files. The new born had a complete clinical exam. Morphological and biological assessment were done to ascertain diagnosis if needed. They were then followed up for $\mathbf{4 8}$ hours. Data were analysed using SPSS. Statistical analyses were mainly descriptive: mean, median, mode and frequency were calculated. Results: During this period, 6048 neonates were examined, 99 of whom had a malformation giving a prevalence of $1.64 \%$. Musculoskeletal defects were the most common $(36.4 \%)$, followed by digestive tract defects $(22.2 \%)$. Ultrasounds were carried out mainly in the second term. Among the malformed babies, only $16.2 \%$ were diagnosed during the prenatal period. The obstetricians did better than radiologist in the prenatal diagnosis of congenital malformations. All the urinary tract malformations and $33.3 \%$ of the polymalformations were diagnosed by prenatal echography. Among the malformed babies, 33\% died within the first 48 hours of life and polymalformed babies were more concerned $(66.7 \%)$. Conclusion: The prevalence of congenital birth defect was $1.64 \%$. The rate of prenatal diagnosis remained low, meanwhile one third of the affected babies die after births. An early diagnosis would anticipate on medical care at birth and allow therapeutics abortions when indicated.

\footnotetext{
${ }^{*}$ Corresponding author.
} 
Keywords

Birth Defects, Prevalence, Antenatal Diagnosis, Outcome, Douala Cameroon

\section{Introduction}

According to the World Health Organization (WHO) birth defects are morphological and functional abnormalities present at birth. They are due to genetic or environmental factors such as infections, metabolic disorders, drugs, ionizing radiation and toxins [1].

Numerous studies on malformation have been published worldwide. WHO estimated in 2004 that $7 \%$ of perinatal death (260,000 neonatal deaths) was due to malformations [1]. These malformations, whether isolated or associated, remain frequent, with an estimate rate of $2 \%-3 \%$ of live births in Canada [2], 3\% in France in 2008 [3], 4.19\% in Australia [4].

These defects are diagnosed during prenatal work-ups especially by ultrasonography or clinically during assessment in the delivery room. However in some cases further laboratory tests are needed for identification or confirmation of these malformations. The prognosis of new-borns with birth defects depends on the type of malformation, the time of diagnosis and the therapeutic options available. Prenatal diagnosis can determine possible post-natal therapeutic options as well as provide justifications for therapeutic termination of these pregnancies when these malformations are incompatible with extra-uterine life.

In our daily practice, ultrasounds are performed by technicians with varying levels of skills and often the sole aim of most parents is gender identification of their babies. We therefore asked the questions: What is the percentage of congenital malformations diagnosed prenatally? How does this diagnosis vary with the different types of malformations and sonographers qualification?

\section{Materials and Methods}

This was a cross-sectional study carried-out in the obstetric and neonatology units of the Douala General Hospital over a period of 3 years 6 months ( $1^{\text {st }}$ January 2008 to 30 June 2012). Douala general hospital is a tertiary hospital located in the main economic town of Cameroon.

All neonates with birds defects observed during birth or transferred in the neonatal unit from other hospitals were included. We obtained consent of all parents and authorisation of the national ethical committee (066/ CNE/SE/12). Sampling was systematic. After fully explaining the purpose and interest of the study to children's parents, consent was obtained. The children's parents were then interviewed, their antenatal medical records were used and in each case, the following data were collected on a fact sheet: the age of the parents, the gravidity and parity of the mother, education level and the gestational age at time of delivery. In the prenatal work-ups of the mothers, results of antenatal ultrasound during the $1^{\text {st }}, 2^{\text {nd }}$ and $3^{\text {rd }}$ term were collected. The first trimester was defined as the period between 0 to 13 weeks 6 days, the 2 nd trimester from the $14^{\text {th }}$ week to 27 weeks 6 days, and the 3rd trimester from the 28 weeks to the end of pregnancy. We noted the qualifications of the sonographer [gynaecologist, radiologist, general practionner or others] and anomalies observed. After delivery, complete clinical examination of the neonate was done; the score for adaptability to extra uterine life (Apgar score), birth weight, type of malformation and outcome after 48 hours of life were recorded. If needed some paraclinical tests like echography, radiology or biology were done to ascertain the diagnosis of congenital malformation.

Data entry and data processing were made using a Microsoft Excel. The results were analysed using CS Pro 4.0 and software Statistical Package for the Social Sciences (SPSS). Statistical analysis was purely descriptive. Mean, median and mode were calculated for quantitative variables and frequencies were used for qualitative variables. We calculate the prevalence of congenital malformations, the proportion of antenatal diagnosis, the percentage of diagnosis according to the sonographer qualification and the type of malformations.

\section{Results}

\subsection{Prevalence and Type of Congenital Malformations}

During the study period, 6048 infants were admitted of which 99 had malformations, giving a prevalence of 
$1.64 \%$.

The most frequent anomalies were of musculoskeletal origin (36.4\%) whereas the least frequent were of the respiratory system (1.0\%). Multiple malformation syndromes represented $18.2 \%$ of all birth defects (Table 1 ).

Polydactyly was the most common isolated anomalies found (24.7\%) followed by omphalocele (8.6\%) (Table 2). Figures 1-5 illustrated some defects diagnosed before and at birth.

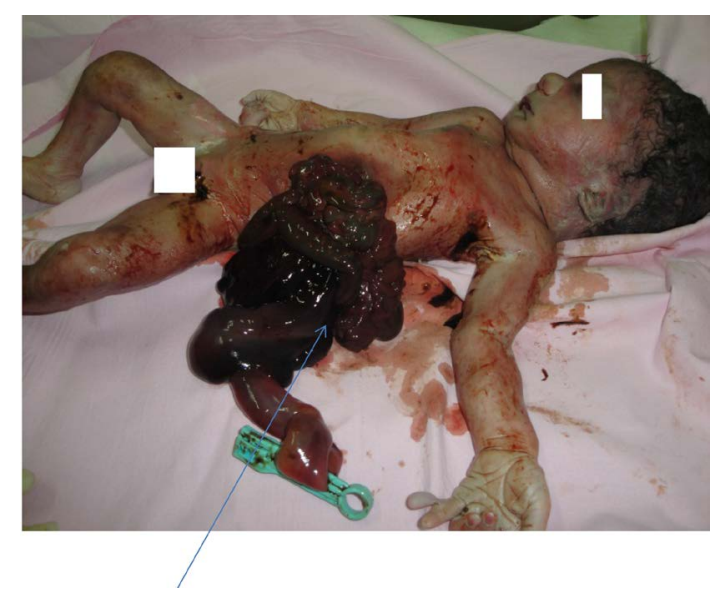

Figure 1. Gastroschisis.

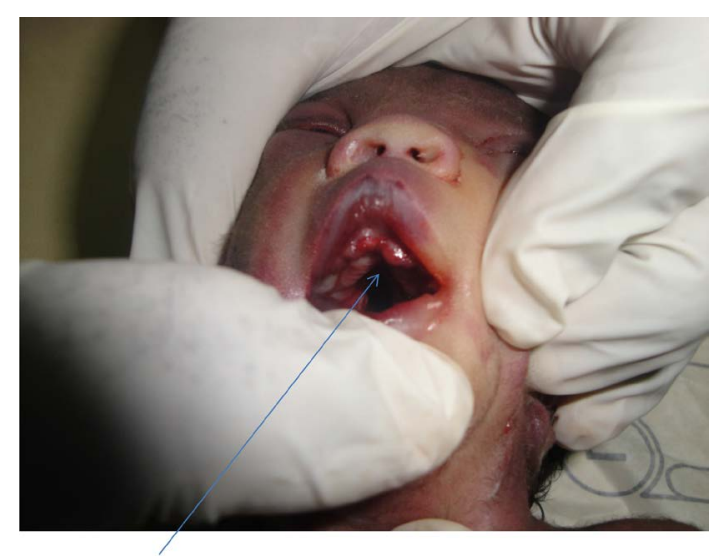

Figure 2. Cleft palate.

Table 1. Congenital anomalies encountered.

\begin{tabular}{ccc}
\hline Nature of abnormalities & Frequency & Percentage \\
\hline Musculo-skeletal & 36 & $36.4 \%$ \\
Digestive & 22 & $22.2 \%$ \\
Poly malformation & 18 & $18.2 \%$ \\
Neural tube & 11 & $11.1 \%$ \\
Heart & 5 & $5.1 \%$ \\
Kidney & 4 & $4.0 \%$ \\
Genital & 2 & $2.0 \%$ \\
Respiratory & 1 & $1.0 \%$ \\
Total & $\mathbf{9 9}$ & $\mathbf{1 0 0} \%$ \\
\hline
\end{tabular}




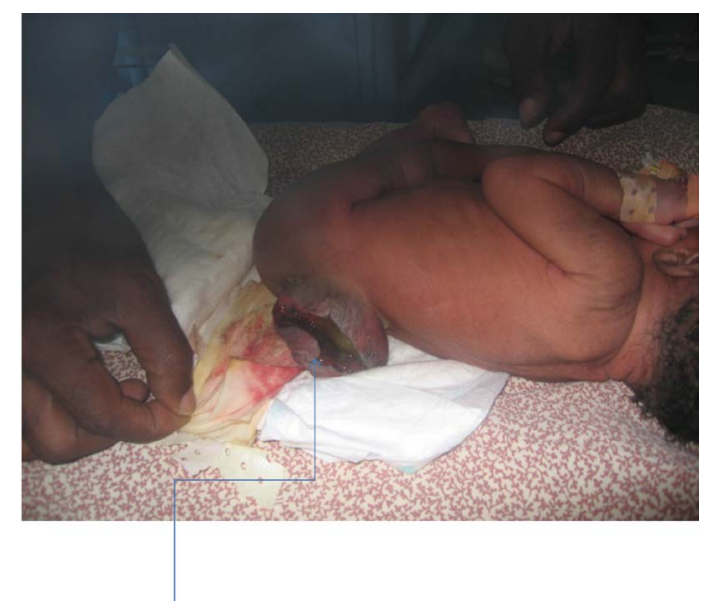

Figure 3. Spina bifida.

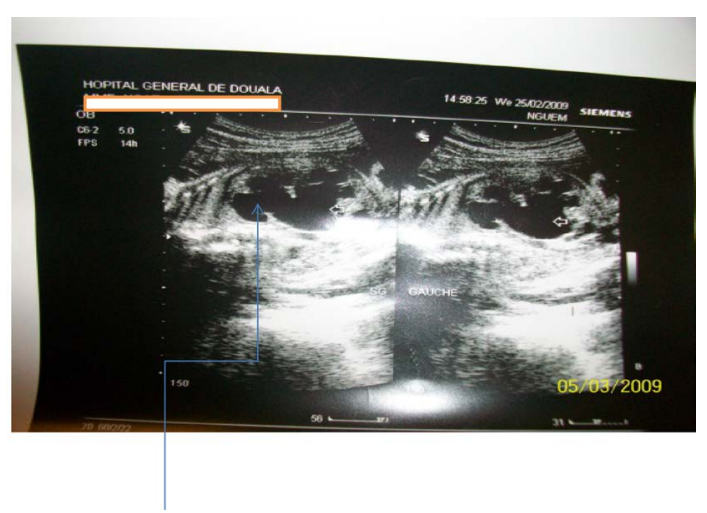

Figure 4. Hydronephrosis.

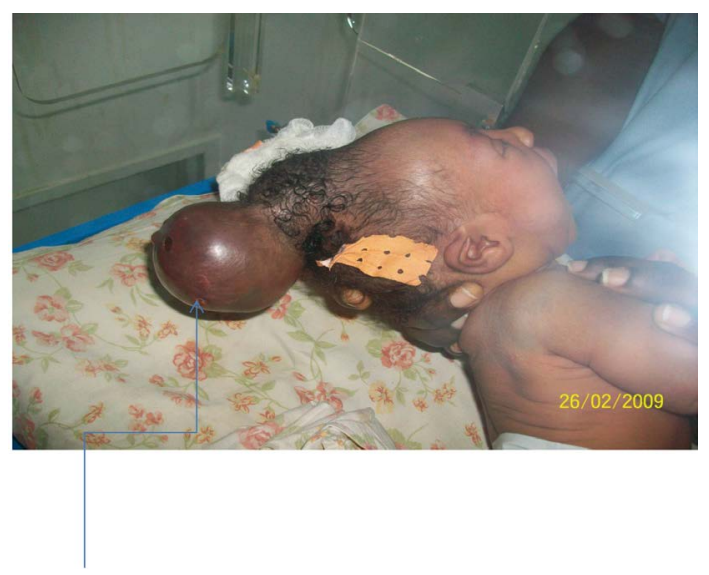

Figure 5. Encephalocele.

Multiple malformation syndromes represented $18.2 \%$ of all defects found. They were represented by the following associations:

Suggestive associations of chromosomal abnormality

- Clubfoot + anal atresia (clinical diagnosis of trisomy 21)

- Sexual Ambiguity + cardiopathy + low-set ears (clinical diagnosis of trisomy 21)

- Omphalocele + clinical diagnosis of trisomy 21

- Jejunal atresia + clinical diagnosis of trisomy 21 
Table 2. Types of isolated anomalies encountered.

\begin{tabular}{|c|c|c|}
\hline Types of anomalies & Frequency & Percentage \\
\hline Polydactyly & 20 & $24.7 \%$ \\
\hline Omphalocele & 7 & $8.6 \%$ \\
\hline Clubfoot & 6 & $7.4 \%$ \\
\hline Multiple skeletal anomalies & 6 & $7.4 \%$ \\
\hline Myelomeningocele & 5 & $6.2 \%$ \\
\hline Oesophageal atresia & 4 & $4.9 \%$ \\
\hline Jejuna atresia & 4 & $4.9 \%$ \\
\hline Spina bifida occulta & 4 & $4.9 \%$ \\
\hline Gastroschisis & 3 & $3.7 \%$ \\
\hline Imperforate anus & 2 & $2.5 \%$ \\
\hline Atrioventricular canal & 2 & $2.5 \%$ \\
\hline Cryptorchidism & 2 & $2.5 \%$ \\
\hline Cleft lip and palate & 2 & $2.5 \%$ \\
\hline Atrophy right leg & 1 & $1.2 \%$ \\
\hline Pyloric stenosis & 1 & $1.2 \%$ \\
\hline Umbilical hernia hypertrophic & 1 & $1.2 \%$ \\
\hline Hydrocephalus & 1 & $1.2 \%$ \\
\hline Encephalocele & 1 & $1.2 \%$ \\
\hline Achondroplasia & 1 & $1.2 \%$ \\
\hline Evisceration of the Heart & 1 & $1.2 \%$ \\
\hline Major leak tricuspid & 1 & $1.2 \%$ \\
\hline Heart defect unidentified & 1 & $1.2 \%$ \\
\hline Choanal stenosis & 1 & $1.2 \%$ \\
\hline Pyélocalicielle expansion & 1 & $1.2 \%$ \\
\hline Bilateral polycystic kidneys & 1 & $1.2 \%$ \\
\hline Hydronephrosis stage IV & 1 & $1.2 \%$ \\
\hline Junction syndrome of the right kidney & 1 & $1.2 \%$ \\
\hline Total & 81 & $100 \%$ \\
\hline
\end{tabular}

- Hydrocephalus + omphalocele + bilateral cryptorchidism (clinical diagnosis of trisomy 21)

- Facial paralysis + fontanelle enlargement extended + microcephaly + posterior cleft palate + deformity of the hands (suspicion of trisomy 18)

- Microcephaly + clubfeet + bilateral polycystic kidney disease (suspicion of trisomy 18)

Neural tube defect

- Spina bifida + Clubfoot + Congenital dislocation of the hip

- Hydrocephalus + syndactyly + myelomeningocele + clubfeet

- Hydrocephalus + clubfoot

Other associations 
- Renal dysplasia + retraction of the elbow + deformity of the ankle

- Malformation of external genitalia + ectromelia+ genu varum

- Agenesis of the upper limbs + anophthalmia + narrow thorax

- Imperforate anus + malformed hands

- Hand dysmorphism + congenital dislocation of the wrist + oesophageal atresia

- Imperforate anus + vulvar malformation + oesophageal atresia

- Imperforate choanal + polydactyly

- Posterior cleft palate + retrognathism + glossoptosis + microcephaly + mild facial paralysis + low-set ears + polydactyly (Pierre Marie Robin Syndrome).

\subsection{Term at Which Echography Was Performed}

Most ultrasounds were carried-out during the second term (48.5\%) and 28.3\% of patient underwent first term echography (Table 3). On average, ultrasounds performed in the first term were done at 10 weeks of gestation, while those in the second term were at the $22^{\text {nd }}$ week and those of the third term at the $34^{\text {th }}$ week of gestation.

\subsection{Antenatal Diagnosis of Congenital Malformations}

Overall, 16.2\% (16 over 99) of malformations were diagnosed during prenatal period. The percentage of prenatal diagnosis was higher with gynaecologists than radiologists and general practitioners regardless of the term at which the ultrasounds were carried-out. A total of 122 ultrasounds were performed (some patients had more than one echography): 58 were done by gynaecologists (prenatal diagnosis of malformations was done in $37.9 \%$ of cases), 59 by radiologists (prenatal diagnosis of malformations was done in 22\% of cases), 02 by general practitioners and 03 by other practitioners (no prenatal diagnosis) (Table 4).

The urogenital malformations had the highest percentage of prenatal diagnosis $66.7 \%$ with $100 \%$ for the diagnosis of renal malformations. Meanwhile, none of the musculo skeletal malformation was diagnosed prenatally (Table 5).

\subsection{Outcome of Malformed New-Borns}

Malformed newborns were mainly born at term (74\%); 56.6\% were males, 39.4\% females and 4\% had an undetermined gender. Still-births represented $6.1 \%$ of the study population. The death rate within the first 48 hours was 33.3\% (including the still-births). The majority (66.7\%) of babies with multiple malformation syndromes died. Cardiopulmonary abnormalities were second cause of mortality with $50 \%$ of death among affected newborns (Table 6).

\section{Discussion}

In our study, the incidence of congenital malformations was 1.64\%. A number of factors made comparisons with similar published studies difficult. These included the study period which varied from one author to another: Coulibaly-Zerbo et al. conducted a study of eight months [4], Tayebi et al. did theirs for 9 months [5]. Ours spanned through a period of 3 years and 6 months; The disparities in sample sizes: Riley et al. had a sample population of 25,231 new-borns [6], Waqas et al. on the other hand had only 621 new-borns in their study [7]. We identified 6048 new-borns during the study period.

Table 3. Number of ultrasound performed according to gestational age.

\begin{tabular}{cccc}
\hline Carried-out or not & $\mathbf{1}^{\text {st }}$ trimester (\%) & $\mathbf{2}^{\text {nd }}$ trimester (\%) & $48(48.5)$ \\
\hline Carried-out & $28(28.3)$ & $18(18.2)$ & $46(46.5)$ \\
Not carried-out & $36(36.4)$ & $33(33.3)$ & $32(21.2)$ \\
Unspecified & $35(35.3)$ & 99 & 99 \\
Total & 99 & $32.3)$ \\
\hline
\end{tabular}

Unspecified ${ }^{*}$ : Not specified in the medical record of the mother, or when the mother was not in possession of the ultrasound results. 
Table 4. Antenatal diagnosis according to the operator and gestational age.

\begin{tabular}{|c|c|c|c|c|c|}
\hline \multirow{2}{*}{ Antenatal diagnosis } & \multicolumn{4}{|c|}{ Examiner (first term ultrasound) } & \multirow{2}{*}{ Total } \\
\hline & gynaecologist & radiologist & $\mathrm{GP}^{*}$ & others & \\
\hline Yes & 7 & 2 & 0 & 0 & 9 \\
\hline No & 8 & 10 & 0 & 1 & 19 \\
\hline Total & 15 & 12 & 0 & 1 & 28 \\
\hline \multirow{2}{*}{ Antenatal diagnosis } & \multicolumn{4}{|c|}{ Examiner (second term ultrasound) } & \multirow{2}{*}{ Total } \\
\hline & Gynaecologist & Radiologist & GP & Others & \\
\hline Yes & 8 & 4 & 0 & 0 & 12 \\
\hline No & 16 & 18 & 1 & 1 & 36 \\
\hline Total & 24 & 22 & 1 & 1 & 48 \\
\hline \multirow{2}{*}{ Antenatal Diagnosis } & \multicolumn{4}{|c|}{ Examiner (third term ultrasound) } & \multirow{2}{*}{ Total } \\
\hline & Gynaecologist & Radiologist & GP & Others & \\
\hline Yes & 7 & 7 & 0 & 0 & 14 \\
\hline No & 12 & 18 & 1 & 1 & 32 \\
\hline Total & 19 & 25 & 1 & 1 & 46 \\
\hline \multirow{2}{*}{ Antenatal diagnosis } & \multicolumn{4}{|c|}{ Examiner (all terms) } & \multirow{2}{*}{ Total } \\
\hline & Gynaecologist & Radiologist & GP & Others & \\
\hline Yes & 22 (37.9\%) & 13 (22\%) & $0(0 \%)$ & $0(0 \%)$ & 35 (28.7\%) \\
\hline No & 36 (62.1\%) & 46 (78\%) & $2(100 \%)$ & $3(100 \%)$ & 87 (77.3\%) \\
\hline Total & 58 & 59 & 2 & 3 & 122 \\
\hline
\end{tabular}

*GP: General Practitionner.

Table 5. Prenatal diagnosis based on the type of malformation.

\begin{tabular}{cccc}
\hline Type of malformation & Prenatal diagnosis (\%) & No prenatal diagnosis (\%) & Total \\
\hline Musculoskeletal & $0(0)$ & $36(100)$ & 36 \\
Digestive & $2(9.1)$ & $20(90.9)$ & 22 \\
Heart and lungs & $1(16.7)$ & $5(83.3)$ & 6 \\
Urogenital & $4(66.7)$ & $2(33.3)$ & 11 \\
Neural tube & $3(27.3)$ & $8(72.7)$ & 18 \\
Poly malformation & $6(33.3)$ & $12(66.7)$ & \\
\hline
\end{tabular}

Table 6. Outcome of the new-borns according to the type of defect.

\begin{tabular}{cccc}
\hline Type of defect & Dead neonate (\%) & Alive neonate (\%) & Total \\
\hline Musculoskeletal & $4(11.1)$ & $32(88.9)$ & 36 \\
Digestive & $10(45.5)$ & $12(54.5)$ & 22 \\
Heart and lungs & $3(50.0)$ & $3(50.0)$ & 6 \\
Urogenital & $1(16.7)$ & $5(83.3)$ & 11 \\
Neural tube & $3(27.3)$ & $8(72.7)$ & 18 \\
Poly malformation & $12(66.7)$ & $6(33.3)$ & 99 \\
\hline
\end{tabular}


Interestingly, the incidence (1.64\%) in our study was similar to that of Amon-Tanohdick et al. (1.85\%) in Abidjan, Côte d'Ivoire and Grover N in India (1.78\%) [8] [9]. Higher incidence was found by Baht BV et al. in South India (3.7\%) and by Dolk H et al. in Europe (2.39\%) [10] [11].

Musculoskeletal defects were the most common in our study. They represented $36.4 \%$ of all defects. These results were similar to those reported by Baht BV et al. who found that musculo-skeletal malformations were the commonest [10]. Some authors like Verma et al. previously found predominance of central nervous system malformation in India [12].

Polydactylism was the most frequent of all isolated birth defects with a rate of $24.7 \%$ and $55 \%$ amongst children with musculoskeletal defects. The fifth finger was usually the most affected and this could be unilateral or bilateral. This is a fairly common abnormality observed amongst black new-borns (mostly located on the fifth finger) which is quite rear amongst whites. Findings published by Monteleone et al. in Brazil, showed a prevalence of $95 \%$ among blacks in comparison to 5\% of whites in a study of 242 cases of polydactyly [13].

Neural tube defects accounted for $11.1 \%$ of the study population. The most common being the myelomeningocele with a rate of $42 \%$, followed by spina bifida, hydrocephalus and encephalocele. This rate was lower than those of Coulibaly-Zerbo et al., Waqas et al. who obtained higher rates of neural tube defects $38.9 \%$ and $33.5 \%$ respectively [4] [7]. It is known that neural tube defects are related to folic acid deficiency; our patients had relatively high socio-economic status permitting them to eat balanced diets, hence less folic acid deficiency.

The poly-malformations concerned $18.2 \%$ of the newborns. However we were unable to associate these anomalities with specific diseases due to inadequate diagnostic means. Despite that, this percentage was lower than that observed by Coulibaly-Zerbo et al. who reported $45.2 \%$ in their study [4]. Suspected cases of trisomy 21 could not be confirmed by karyotyping due to the unavailability of this technique in our country.

In our study, prenatal diagnosis was made solely by obstetric ultrasound; $16.2 \%$ of the malformations were diagnosed prenatally. These included polymalformation, renal, cardiac, digestive and neural tube defects. No musculoskeletal malformation was diagnosed prenatally. This percentage is very low when compared to the $61 \%$ or $64 \%$ of antenatal diagnosis rate (major and minor malformations) in European hospitals [14] [15]. Seventy percent of foetal malformations are detected prenatally by sonographers in Paris [16]. This difference places us thirty years back in this field [17]. This can be due to lack of well-trained physician, lack of good ultrasound machines, poverty (some patient are not able to pay for their antennal care).

Urogenital malformations had a higher rate of prenatal diagnosis (66.7\%), this corroborates some findings in some literature reviews. Indeed, urogenital abnormalities are easier to detect prenatally as compared to cardiovascular malformations for example. In a study entitled Eurofetus, 89\% of urogenital anomalies, 88\% of central nervous system abnormalities were detected prenatally whereas only $34 \%$ of heart defects were detected [18].

The rate of antenatal diagnosis was higher among gynaecologists than radiologists. Antenatal diagnosis of birth defects strongly depends on the qualification of the sonographer [14].

The mean gestational ages with respect to the $1^{\text {st }}, 2^{\text {nd }}$, and $3^{\text {rd }}$ trimesters during which most ultrasound scans were done were the $10^{\text {th }}, 22^{\text {nd }}$, and $34^{\text {th }}$ weeks respectively. Moreover, the highest number of ultrasounds was performed during the second term. According to the recommendations of the French foetal ultrasound college, in order to obtain optimal results for prenatal diagnosis of birth defects, ultrasounds should be performed between the $11^{\text {th }}-13^{\text {th }}$ week +6 days for the $1^{\text {st }}$ term, between the $20^{\text {th }}-25^{\text {th }}$ week for the second term and between the $30^{\text {th }}$ and $35^{\text {th }}$ week for the third term [19]. The second term echography should be the most important because it is the best period within which foetal abnormalities are most observable. We observed that the timing of the first term ultrasound in our study was not correct; this could have contributed to the low rate of prenatal diagnosis observed? By performing $1^{\text {st }}$ term ultrasounds at 10 weeks of gestation, early morphological abnormalities and abnormal nuchal translucency are not quit visible; thus abnormal pregnancies don't receive the special attention which it's due. We would like to mention that there is no social security in Cameroon and every patient have to pay for her prenatal test. Those who don't have enough money may delay their exams (and not respect their appointment) or not do it at all.

The death rate among neonates was 33.3\%. This rate was lower than that of Amon-Tanoh-Dick et al. which was $48 \%$ of malformed neonates [8]. The highest death rate was found in neonates with multiple malformations. This is explained by the fact that multiple malformations prevent a harmonious development of the foetus with subsequent multi-organ failure.

Limitations of the study concern the multiplicities of centers in which ultrasound examinations were carried 
out and the ultrasound machine used were different from one center to another. It is true that good ultrasound machines allow better prenatal diagnosis of congenital malformations. Furthermore, due to the lack of funding for the study, patients had to pay for their ultrasound examinations. Thus, because of lack of money, they did not always respect their appointment for an ultrasound. We know it is for example more difficult to study foetal morphology in the third than second trimester.

\section{Conclusion}

Over all, the prevalence of congenital malformations remains low in this study. Polydactyly seems to be an African specificity. The rate of prenatal diagnosis remains very low (16.2\%) in comparison with the European rate (61\%); meanwhile one third of the affected babies die within 48 hours after births. An early diagnosis would anticipate on medical care for malformed babies at birth and should allow therapeutics abortions in case of major malformation incompatible with extra uterine life. Physicians should be well trained, in order to increase the prenatal diagnosis rate of congenital malformations.

\section{Acknowledgements}

Thanks to the staff for their help in recruiting patients.

\section{Conflicts of Interest}

The authors do not declare any conflict of interest.

\section{Contribution of Authors}

All authors contributed in the project conception, data collection and analysis, drafting and proof reading the manuscript.

\section{References}

[1] Geneva, WHO. The Sixty-Third World Assembly of the Health. http://apps.who.int/gb/ebwha/pdf_files/WHA63-REC1/WHA63_REC1-en.pdf

[2] Harper, P.S. (1998) Practical Genetic Counselling. 5th Edition, Butterworth Heinemann, Boston.

[3] Perthus, I., Amar, E., De Vigan, C., Doray, B. and Francannet, C. (2008) Registries of Congenital Malformations in France: Situation in 2008. BEH, 28-29, 246-248.

[4] Coulibaly-Zerbo, F, Amorissani-Folquet, F., Kacou-Kakou, A., Sylla, M., Noua, F, Kramo, E., Yapo, G., Do Rego, A., Prince, A., Toure, M., Houenou, Y. and Kouame Konan, J. (1997) Epidemiological Study of the Congenital Malformation. Médecine d'Afrique Noire, 44, 411-414.

[5] Tayebi, N., Yazdani, K. and Naghshin, N. (2010) The Prevalence of Congenital Malformations and Its Correlation with Consanguineous Marriages. Oman Medical Journal, 25, 37-40. http://dx.doi.org/10.5001/omj.2010.9

[6] Riley, M.M., Halliday, J.L. and Lumley, J.M. (1998) Congenital Malformations in Victoria, Australia, 1983-95: An Overview of Infant Characteristics. Journal of Paediatrics and Child Health, 34, 233-240. http://dx.doi.org/10.1046/j.1440-1754.1998.00208.x

[7] Waqas, J., Farooq, A., Taimoor, J. and Muhammad, S.M. (2009) Prevalence of Gross Congenital Malformations at Birth in the Neonates in a Tertiary Care Hospital. A.P.M.C., 3, 47-50.

[8] Amon-Tanoh-Dick, F., Gouli, J.C., N’Gouan-Domoua, A.M., Aka, J. and Napon-Kini, H. (2006) Epidemiology and Immediate Neonatal Outcome of New Borns with Congenital Malformations in CHU de Yopougon Abidjan-Cote d’Ivoire. Revue internationale des Sciences Médicales, 8, 7-12.

[9] Grover, N. (2000) Congenital Malformations in Shimla. The Indian Journal of Pediatrics, 67, 249-251. http://dx.doi.org/10.1007/BF02758158

[10] Bhat, B.V. and Babu, L. (1998) Congenital Malformations at Birth—A Prospective Study from South India. The Indian Journal of Pediatrics, 65, 873-881. http://dx.doi.org/10.1007/BF02831352

[11] Dolk, H., Loane, M. and Garne, E. (2010) The Prevalence of Congenital Anomalies in Europe. Advances in Experimental Medicine and Biology, 686, 349-364. http://dx.doi.org/10.1007/978-90-481-9485-8_20

[12] Verma, M., Chhatwal, J. and Singh, D. (1991) Congenital Malformations-A Retrospective Study of 10,000 Cases. 
The Indian Journal of Pediatrics, 58, 245-252. http://dx.doi.org/10.1007/BF02751129

[13] Monteleone-Neto, R. and Castilla, E.E. (1994) Apparently Normal Frequency of Congenital Anomalies in the Highly Polluted Town of Cubatao, Brazil. American Journal of Medical Genetics, 52, 319-323. http://dx.doi.org/10.1002/ajmg.1320520313

[14] Levi, S. (2004) Prenatal Screening of Congenital Birth Defects. Revue Hospitals. BE., 2.

[15] Garne, E., Loane, M., Dolk, H., De Vigan, C., Scarano, G., Tucker, D., Stoll, C., Gener, B., Pierini, A., Nelen, V., Rösch, C., Gillerot, Y., Feijoo, M., Tincheva, R., Queisser-Luft, A., Addor, M.C., Mosquera, C., Gatt, M. and Barisic, I. (2005) Prenatal Diagnosis of Severe Structural Congenital Malformations in Europe. Ultrasound in Obstetrics \& Gynecology, 25, 6-11. http://dx.doi.org/10.1002/uog.1784

[16] Jouannic, J.-M. (2005) The Sonographer, the Fetus and the Epidemiologist. JGYN., 34, 7.

[17] De Vigan, C., Khoshnood, B., Lhomme, A., Vodovar, V., Goujard, J. and Goffinet, F. (2005) Prevalence and Prenatal Diagnosis of Congenital Malformations in the Parisian Population: Twenty Years of Surveillance by the Paris Registry of Congenital Malformations. Journal de Gynécologie Obstétrique et Biologie de la Reproduction, 34, 8-16. http://dx.doi.org/10.1016/S0368-2315(05)82665-1

[18] Levi, S. (2003) Mass Screening for Fetal Malformations: The Eurofetus Study. Ultrasound in Obstetrics \& Gynecology, 22, 555-558. http://dx.doi.org/10.1002/uog.935

[19] Claude Sureau, C. and Henrion, R. (2005) Le rapport du comité technique de l'échographie de dépistage prénatal. http://www.cfef.org/archives/lettres/DocusCTE/rapportCTE.pdf 